\title{
Rootfinding : An Iterative Tool to Solve Different Problems
}

\author{
Iswarmani Adhikari \\ Department of Mathematics, PN Campus, Pokhara \\ adhikariim35@gmail.com
}

\begin{abstract}
The aim of this paper is to apply the iteration methods for the solution of non-linear equations. Among the various rootfinding techniques, two of the common iterative methods Regula-falsi (false position) and the Secant method are used in two different problems to show the applications of numerical analysis in different fields.
\end{abstract}

Keywords: Non linear equation, Iteration, Regula-falsi and Secant method.

\section{INTRODUCTION:}

Numerical analysis can be applied to solve the complex numerical problems only by the use of simple arithmetic operations and helps to develop and evaluate different methods for computing numerical results from given data. The methods of computation are the algorithms.

There are various algorithms and there is no hard and fast rule for choosing one algorithm over another for the rootfinding but we take into account their speed and accuracy on computing.

The given data be rarely exact. So, there are errors in the information. The algorithm itself introduces some errors. Thus, the output information will then contain errors from both of these sources. So the errors be,

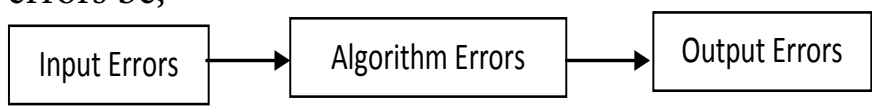

\section{RESULT \& DISCUSSION}

Solution of a non-linear equation $\mathrm{f}(\mathrm{x})=0$ is the number $\alpha$ for $f(\alpha)=0$. Solving such equations is simply the rootfinding. General non-linear equations of degree $\mathrm{n}$ can be solved with iteration methods. Bracketing and open are two major methods for its solution. Bisection and Regula-falsi are two common bracketing methods where as the common open methods are Newton's method, Secant method and the Fixed Point Iteration methods. In the following two examples, the Regula-falsi and the Secant methods are applied respectively.
Regula-falsi is the variation of bisection method, instead of computing the mid-point as in bisection method, it computes the intersection of the $\mathrm{x}$-axis and the chord. The intersection of the chord ( $a, f(a))$ and $(b, f(b))$ with $x$-axis is an approximation, for faster convergence.

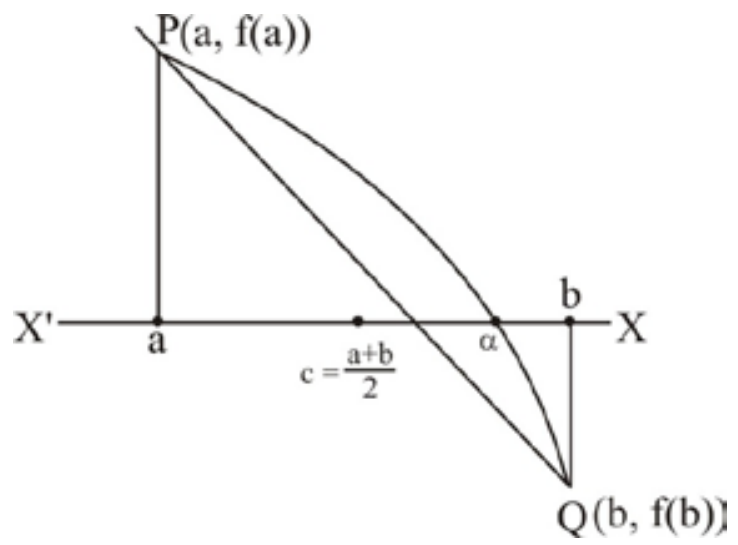

Figure I

Equation of chord PQ be $\frac{y-f(a)}{x-a}=\frac{f(b)-f(a)}{b-a}$.

For $x$-axis, $y=0$ then $x=a-\frac{(b-a) f(a)}{f(b)-f(a)}$

or, $x=b-\frac{(b-a) f(b)}{f(b)-f(a)}$.

For the respective iterations we apply,

$$
\begin{aligned}
& p_{1}=b_{1}-f\left(b_{1}\right) \frac{b_{1}-a_{1}}{f\left(b_{1}\right)-f\left(a_{1}\right)}, \\
& p_{2}=b_{2}-f\left(b_{2}\right) \frac{b_{2}-a_{2}}{f\left(b_{2}\right)-f\left(a_{2}\right)}, \text { and so on. }
\end{aligned}
$$

Newton's method is the best known procedure for finding the roots of an non-linear equation. It is the fastest method, but requires analytical computation of 
the derivative of $\mathrm{f}(\mathrm{x})$. Also, the method may not always converge to the desired root. So, itshould betaken care of.

Starting with a $\mathrm{x}_{\mathrm{o}}$ that is close to a root $\alpha$, Newton's method uses the following to compute $\mathrm{x}_{1}, \mathrm{x}_{2}, \ldots$ until $x_{k}$ converges to $\alpha$, where $x_{i+1}=x_{i}-\frac{f\left(x_{i}\right)}{f^{\prime}\left(x_{i}\right)}$

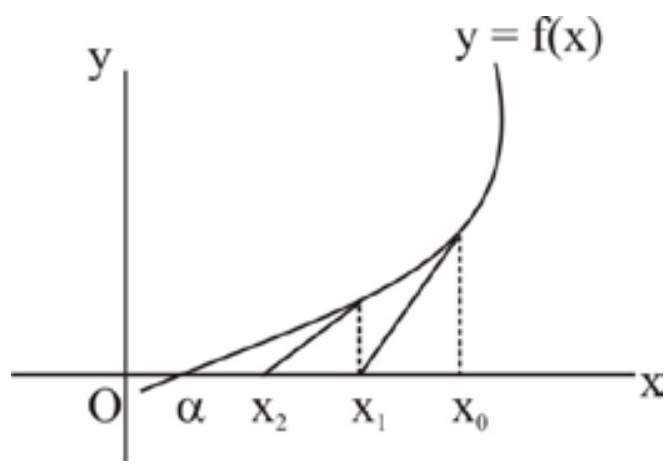

Figure 2

But the Newton's method fails to apply if $f^{\prime}\left(x_{i}\right)$ is difficult to calculate or is unavailable. In such case, $\mathrm{g}_{\mathrm{k}}$, the approximation to $\mathrm{f}^{\prime}(\mathrm{x})$ is used for it and,

$$
x_{i+1}=\frac{x_{i}-f\left(x_{i}\right)}{g_{i}} \text { where the slope of the chord }
$$

between $x_{i-1}$ and $x_{i}$ be $g_{i}=\frac{f\left(x_{i}\right)-f\left(x_{i-1}\right)}{x_{i}-x_{i-1}}$.

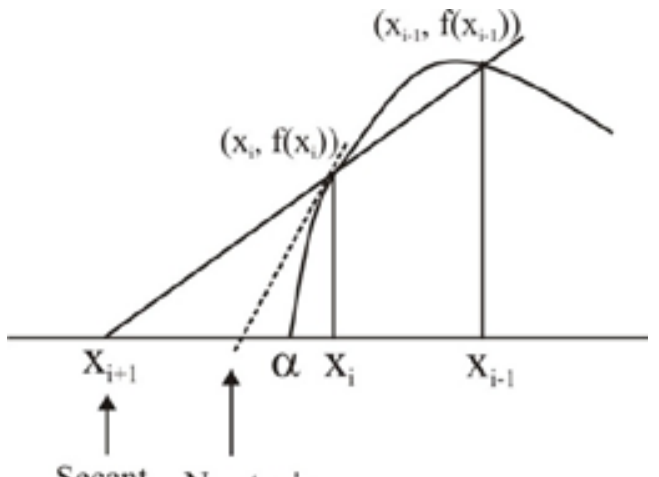

Secant Newton's

method method

Figure 3

Then the Secant method formula becomes, $x_{i+1}=x_{i}-\frac{x_{i}-x_{i-1}}{f\left(x_{i}\right)-f\left(x_{i-1}\right)} \times f\left(x_{i}\right)$.

For the respective iterations we apply,

$$
p_{2}=p_{1}-f\left(p_{1}\right) \frac{p_{1}-p_{0}}{f\left(p_{1}\right)-f\left(p_{0}\right)}, \quad p_{3}=p_{2}-f\left(p_{2}\right) \frac{p_{2}-p_{1}}{f\left(p_{2}\right)-f\left(p_{1}\right)},
$$

and so on.

\section{SOME EXAMPLES:}

\section{Example 1 (Depth of submersion)}

Let a uniform spherical ball of radius $R$ sinks into a fluid (or water), how to know the depth upto which the object sinks?

According to Archimedes' principle, the object will sink to the depth at which the weight of the fluid displaced by the object equals the weight of the object.

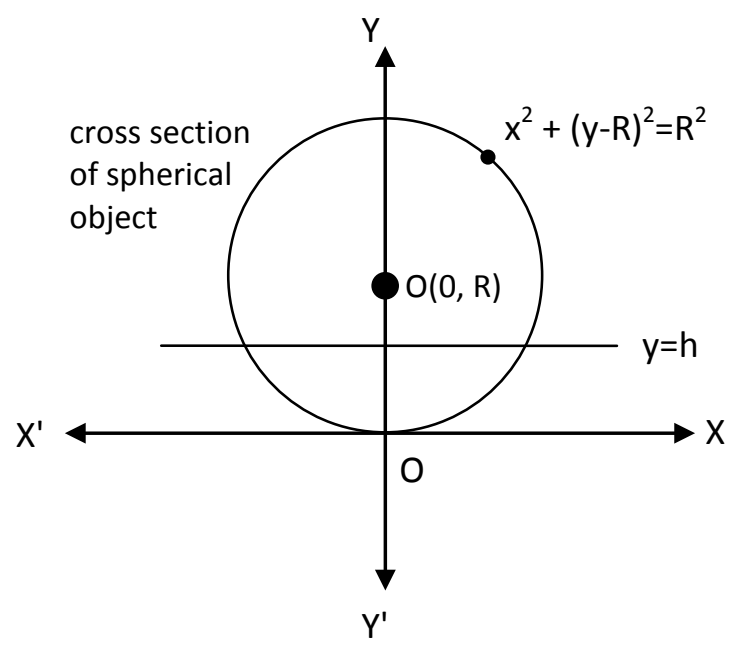

Let, $\mathrm{R}=$ Radius of uniform spherical ball,

$\rho_{0}=$ constant mass density of the ball.

Then, mass of the ball $=\frac{4}{3} \pi R^{3} \rho_{0}$

and, weight of the ball $=\frac{4}{3} \pi R^{3} \rho_{0} g$

Assume,

$\rho_{\mathrm{f}}=$ fluid density,

$\mathrm{v}_{\mathrm{d}}=$ volume of the fluid displaced by the spherical ball.

Then, weight of the fluid displaced $=\rho_{\mathrm{f}} \mathrm{v}_{\mathrm{d}} \mathrm{g}$

Let, $\mathrm{h}=$ depth upto which the object will sink in the fluid.

Then, volume of the fluid displaced, 


$$
\begin{aligned}
\mathrm{V}_{\mathrm{d}} \quad & =\pi \int_{0}^{h} x^{2} d x \\
& =\pi \int_{0}^{h}\left[R^{2}-(y-R)^{2}\right] d x \\
& =\pi \int_{0}^{h}\left(2 R y-y^{2}\right) d x \\
& =2 \mathrm{R} \pi \frac{\mathrm{y}^{2}}{2}{ }^{h}-\pi \frac{y^{3}}{3} h^{h} \\
& =\pi \mathrm{h}^{2}\left(\mathrm{R}-\frac{\mathrm{h}}{3}\right) .
\end{aligned}
$$

$\therefore$ Weight of the displaced fluid $=\rho_{\mathrm{f}} \mathrm{g} \mathrm{ph}^{2}\left(\mathrm{R}-\frac{\mathrm{h}}{3}\right)$

Hence, by Archimede's principle,

$$
\begin{aligned}
& \pi \mathrm{R}^{3} \rho_{0} g=\rho_{\mathrm{f}} g \mathrm{ph}^{2}\left(\mathrm{R}-\frac{\mathrm{h}}{3}\right) \\
& \therefore \quad \rho_{\mathrm{f}} \frac{\mathrm{h}^{3}}{3}-\mathrm{R} \rho_{\mathrm{f}} \mathrm{h}^{2}+\frac{4}{3} \mathrm{R}^{3} \rho_{0}=0
\end{aligned}
$$

Then for given values of $R, \rho_{0}$ and $\rho_{f}$ the depth to which the object sinks (not fully submerged) can be determined by solving the non-linear equation (iii) for h.

In particular, let $\mathrm{R}=5 \mathrm{~cm}$,

$\rho_{0}=0.120 \mathrm{gm} / \mathrm{cm}^{3}$,

$\rho_{\mathrm{f}}=0.890 \mathrm{gm} / \mathrm{cm}^{3}$, (as motor oil).

Then the non-linear equation (iii) becomes,

$$
\frac{0.89}{3} h^{3}-5 \times 0.89 h^{2}+\frac{4}{3} \times 5^{3} \times 0.12=0 .
$$

$\therefore \mathrm{f}(\mathrm{h})=\mathrm{h}^{3}-15 \mathrm{~h}^{2}+67.4157=0$

Let us run through the method of false position (Regula-falsi).

So, for first iteration, let $\left(a_{1}, b_{1}\right)=(0,10)$ where $\mathrm{f}\left(\mathrm{a}_{1}\right)=67.4157>0$ and $\mathrm{f}\left(\mathrm{b}_{1}\right)=\mathrm{f}(10)=-432.5843<0$. Our first approximation to the location of the zero is then,

$$
p_{1}=b_{1}-f\left(b_{1}\right) \frac{b_{1}-a_{1}}{f\left(b_{1}\right)-f\left(a_{1}\right)}=10-\frac{(-432.5843)(10-0)}{-432.5843-63.4157}=1.2785
$$

To determine whether the zero is contained in $\left(\mathrm{a}_{1}, \mathrm{p}_{1}\right)=(0,1.2785)$ or, $\left(\mathrm{p}_{1}, \mathrm{~b}_{1}\right)=(1.2785,10)$, we calculate,

$\mathrm{f}\left(\mathrm{p}_{1}\right)=41.9871>0$. So, the zero is in between $\mathrm{p}_{1}$ and $\mathrm{b}_{1}$.
Then, for the next iteration $\left(a_{2}, b_{2}\right)=\left(p_{1}, b_{1}\right)=$ $(1.2785,10)$

Where,

$$
p_{2}=b_{2}-f\left(b_{2}\right) \cdot \frac{b_{2}-a_{2}}{f\left(b_{2}\right)-f\left(a_{2}\right)}=10-\frac{(-432.5843) \cdot(10-1.2785)}{-432.5843-41.9871}=2.0501
$$

Here, $f\left(p_{2}\right)=12.9884>0$. So, the zero is in between $\mathrm{P}_{2}$ and $\mathrm{b}_{2}$.

So, we take $\left(\mathrm{a}_{3}, \mathrm{~b}_{3}\right)=\left(\mathrm{p}_{2}, \mathrm{~b}_{2}\right)=(2.0501,10)$.

In the third iteration, we calculate,

$$
P_{3}=b_{3}-f\left(b_{3}\right) \cdot \frac{b_{3}-a_{3}}{f\left(b_{3}\right)-f\left(a_{3}\right)}=10-\frac{(-432.5843)(10-2.0501)}{(-432.5843-12.9884)}=2.2818
$$

Here, $\mathrm{f}\left(\mathrm{p}_{3}\right)=1.1970>0$.

So, the zero is in between $\mathrm{p}_{3}$ and $\mathrm{b}_{2}$.

So, we take $\left(\mathrm{a}_{4}, \mathrm{~b}_{4}\right)=\left(\mathrm{p}_{3}, \mathrm{~b}_{2}\right)=(2.2818,10)$.

In the fourth iteration, we calculate,

$$
P_{4}=b_{4}-f\left(b_{4}\right) \cdot \frac{b_{4}-a_{4}}{f\left(b_{4}\right)-f\left(a_{4}\right)}=10-\frac{(-432.5843)(10-2.2818)}{(-432.5843-1.1970)}=2.3031
$$

Here $\mathrm{f}\left(\mathrm{p}_{4}\right)=0.0679>0$.

So, the zero is in between $\mathrm{p}_{4}$ and $\mathrm{b}_{2}$.

So, we take $\left(a_{5}, b_{5}\right)=\left(p_{4}, b_{2}\right)=(2.3031,10)$

In the fifth iteration, we calculate

$$
P_{5}=b_{5}-f\left(b_{5}\right) \frac{\left(b_{5}-a_{5}\right)}{f\left(b_{5}\right)-f\left(a_{5}\right)}=10-\frac{(-432.5843)(10-2.3031)}{(-432.5843-0.0679)}=2.3043 .,
$$

and so on.

In this case, the absolute error $2.2 \times 10^{-3}$, be negligible. Thus, the spherical ball sinks to a depth of roughly $2.3043 \mathrm{~cm}$ in the motor oil.

\section{Example 2 (Solving a crime)}

Commissioner $A$ has been found dead in his office. At $8.00 \mathrm{pm}$, the county coroner determined the core temperature of the corpse to be $90^{\circ} \mathrm{F}$. One hour later, the core temperature had dropped to $85^{\circ} \mathrm{F}$.

Maintenance reported that the building's air conditioning unit broke down at 4:00 pm The temperature in the commissioner's office was $68^{\circ} \mathrm{F}$ at that time. The computerized climate control system recorded that the office temperature rose at $1^{\circ} \mathrm{F}$ per hour after the air conditioning stopped working.

Captain $C$ believes that the infamous Dr. B killed the commissioner. Dr. B, however claims that he has an alibi. Prof. Sharma was interviewing him at his cabin, just across the street from the commissioner's 
office. The receptionist of Prof Sharma checked Dr. $B$ into the cabin at 6:35 pm and the interview tapes confirm that Dr. B was occupied from 6:40 pm until 7:15 pm. Is it possible Dr. B killed the commissioner?

To answer this question, we need to determine the time of death from these information.

We will assume that the core temperature of the corpse was $98.6^{\circ} \mathrm{F}$ at the time of death and began to decrease immediately following death.

We will further assume that the decrease in core temperature proceeded according to Newton's law of cooling as, "the temperature of an object will change at a rate proportional to the difference between the temperature of the object and surrounding".

Let $\mathrm{T}(\mathrm{t})$ denotes the core temperature of the corpse, as the function of time.

Consider $\mathrm{t}=0$ corresponding to $8: 00 \mathrm{pm}$, then we have $\mathrm{T}(0)=90$ and $\mathrm{T}(1)=85$--- (1)

As the office temperature at $4 \mathrm{pm}$ was $68^{\circ} \mathrm{F}$ and increased by $1^{\circ} \mathrm{F}$ per hour, so that at $8 \mathrm{pm}$ it becomes $72^{\circ} \mathrm{F}$.

Then, $\mathrm{T}_{\text {office }}=72+\mathrm{t}$.

By Newton's law of cooling,

$$
\frac{\mathrm{dT}}{\mathrm{dt}}=-\mathrm{k}(\mathrm{T}-72-\mathrm{t})
$$

(2) for $\mathrm{k}$ be the positive constant of proportionality.

The equation (2) can be written as the linear differential equation,

$$
\frac{\mathrm{dT}}{\mathrm{dt}}+\mathrm{kT}=\mathrm{k}(72+\mathrm{t})
$$

(3), with the integrating factor (I.F.) $=\mathrm{e}^{\mathrm{j} \mathrm{kdt}}=\mathrm{e}^{\mathrm{kt}}$.

Where the solution takes the form,

$$
\begin{aligned}
& T \times I . F .=\int k(72+t) \times(I . F .) d t \\
& \begin{aligned}
\Rightarrow T \times e^{k t} & =\int k(72+t) \cdot e^{k t} d t \\
& =\frac{k(72+t) e^{k t}}{k}-\int k \frac{e^{k t}}{k} d t \\
& =(72+t) e^{k t}-\frac{e^{k t}}{k}+C \\
\therefore T & =\left(72+t-\frac{1}{k}\right) e^{k t}+C e^{-k t}
\end{aligned}
\end{aligned}
$$

for $\mathrm{C}$ be the constant of integration.

$$
\begin{aligned}
& \text { From }(1), T(0)=90 \Rightarrow 90=72-\frac{1}{k}+C . \\
& \therefore C=\frac{1}{k}+18 .---------(5)
\end{aligned}
$$

Where, $T(1)=85 \Rightarrow 73-\frac{1}{k}+\left(18+\frac{1}{k}\right) e^{-k}=85$

$$
\therefore f(k)=-12-\frac{1}{k}+\left(18+\frac{1}{k}\right) e^{-k} \text {. }
$$

It can not be solved explicity for $\mathrm{k}$. So, we will have to settle an approximate solution. Once the value of $\mathrm{k}$ has been determined the time of death $t_{d}$ is determined by the help of equation (4) as,

$$
72+t_{d}-\frac{1}{k}+e^{-k t}\left(\frac{1}{k}+18\right)=98.6
$$

where $t_{d}$ measured in hours and 98.6 be the assumed temperature (T). But, equation (7) can not be solved explicity for $t_{d}$; such equations can only be solved by iterative methods.

For secant method

Let, $\mathrm{p}_{0}=0.1$ and $\mathrm{p}_{1}=1$ as $\mathrm{f}\left(\mathrm{p}_{0}\right)=3.3354>0$ and $\mathrm{f}\left(\mathrm{p}_{1}\right)$ $=-6.0103<0$.

Then, $p_{2}=p_{1}-f\left(p_{1}\right) \frac{p_{1}-p_{0}}{f\left(p_{1}\right)-f\left(p_{0}\right)}=1-\frac{(-6.0103)(1-0.1)}{-6.0103-3.3354}=0.4212$

$$
p_{3}=p_{2}-f\left(p_{2}\right) \frac{p_{2}-p_{1}}{f\left(p_{2}\right)-f\left(p_{1}\right)}=0.4212-\frac{(-1.0034)(0.4212-1)}{(-1.0034+6.0103)}=0.3052
$$

Likewise, $\quad p_{4}=p_{3}-f\left(p_{3}\right) \frac{p_{3}-p_{2}}{f\left(p_{3}\right)-f\left(p_{2}\right)}=0.3385$

and $p_{5}=p_{4}-f\left(p_{4}\right) \frac{p_{4}-p_{3}}{f\left(p_{4}\right)-f\left(p_{3}\right)}=0.337114$

with an error as e $<5 \times 10^{-7}$, be negligible.

For this value of $\mathrm{k}$, the equation (7) becomes,

$$
f\left(t_{d}\right)=-26.6+t_{d}-\frac{1}{0.337114}+\left(18+\frac{1}{0.337114}\right) e^{-0.337114 t d} .
$$

Let

$\mathrm{p}_{0}=-2$ and $\mathrm{p}_{1}=0$ as $\mathrm{f}\left(\mathrm{p}_{0}\right)=9.5805>0$ and $\mathrm{f}\left(\mathrm{p}_{1}\right)=-8.6<0$.

Then $p_{2}=p_{1}-f\left(p_{1}\right) \frac{p_{1}-p_{0}}{f\left(p_{1}\right)-f\left(p_{0}\right)}=0.9461$, where

$$
p_{3}=p_{2}-f\left(p_{2}\right) \frac{p_{2}-p_{1}}{f\left(p_{2}\right)-f\left(p_{1}\right)}=-1.174
$$

Likewise, $\mathrm{p}_{4}=-1.1294$ and $\mathrm{p}_{5}=-1.1309$

Thus the time of death was roughly $1 \mathrm{hr}$ and 8 minutes prior to $8 \mathrm{pm}$, that is $6.52 \mathrm{pm}$, which is right in the middle of Dr. B's interview with prof. Sharma.

So, Dr. B could not have killed the commissioner. 


\section{CONCLUSION}

Applied mathematics starts with some real-worlds problems followed by some axioms, postulates, principles, etc to develop a set of assumptions and a set of equations, as a mathematical model, which will be used for subsequent analysis to determine the approximate solution for different mathematical problems that commonly arise during the real-world phenomena. These will include such tasks as the rootfinding, which requires the use of some iterative numerical approximation techniques.

\section{REFERENCES}

1. A. Ralston and P. Rabinowtiz (1978). A First Course in Numerical Analysis. Mc GrawHill, Newyork.

2. Brain Bradie (2007). A Friendly Introduction to Numerical Analysis. Prentice Hall, India.

3. J. Stoer and R. Bulirsch (1991). Introduction to Numerical Analysis. Springer verlang, New York.

4. Kendall E. Atkinson (2008). An Introduction to Numerical Analysis. Wiley, India

5. Richard L. Burden and J.D. Faires (2010). Numerical Analysis. Brooks/cole, Canada. 